\title{
Additional description Of a NeW SPECIES OF TUNGA (SiPHONAPTERA) FROM ECUADOR
}

\author{
PAMPIGLIONE S.*, TRENTINI M.**, FIORAVANTI M.L.*, ONORE G.*** \& RIVASI F.****
}

A new species of chigoe flea belonging to the genus Tunga trimamillata, was recently described by Pampiglione et al. (2002). A better description and more details of the epidemiology of the flea are now presented. It is a species found in goats, pigs and cattle in Santa Isabel in Andean Ecuador. This new species differs from its most similar congener, Tunga penetrans (L., 1758), by several features, the most important of which are a) the presence on the anterior extremity of the gravid female of three rounded humps surrounding the head and thorax / which, however, are not visible if viewed in profile), b) slightly larger dimensions and c) the length of the first segment of the maxillary palpi which is longer than each of the other three.

KEY WORDS : Siphonaptera, Tunga, chigoes, Ecuador, goats, pigs, cattle.

\section{Summary:} Jarocki, 1838 (Siphonaptera, Pulicidae, Tunginae), Tunga

Résumé : DESCRIPTION COMPLÉMENTAIRE D'UNE NOUVELLE ESPÈCE DE TUNGA (SIPHONAPTERA) DE L'ÉQUATEUR

Une nouvelle espèce de chique appartenant au genre Tunga Jarocki, 1838 (Siphonaptera, Pulicidae, Tunginae), Tunga trimamillata, a été récemment décrite par Pampiglione et al. (2002). Les auteurs donnent ici une meilleure description et plusieurs détails de l'épidémiologie de cette nouvelle espèce. La chique a été trouvée dans la localité andine de Santa Isabel, en Équateur, chez des chèvres, des porcs et des bouts. La nouvelle espèce se différencie de la plus proche espèce de ce genre, Tunga penetrans (L., 1758), par plusieurs caractères morphologiques, les plus importants étant constitués par : a) la présence à l'extrémité antérieure de la femelle gravide de trois protubérances encerclant la tête et le thorax qui, toutefois, ne sont pas visibles en observation de profil ; bl des dimensions légèrement plus grandes; cl le premier segment des palpes maxillaires qui est le plus long des quatre.

MOTS CLÉS : Siphonaptera, Tunga, chiques, Équateur, chèvre, porc, boeuf.

in the XXII Congress of the Italian Society of Parasitology (Pampiglione et al., 2002). Now, a better description and more details of its epidemiology are here presented.

\section{MATERIALS AND METHODS}

to assign them to any known species of the genus Tunga (Traub, 1950; Hopkins \& Rothschild, 1953; Smit, 1962). At that time, there were too few specimens available to reach a firm conclusion regarding their identity. Since then, one of us (G.O.) has collected more chigoes from goats and cattle in the same locality and further study has confirmed that they are a new species of Tunga which was described and named Tunga trimamillata $\mathrm{n}$. $\mathrm{sp}$. in a short communication

\footnotetext{
* Dipartimento di Sanità Pubblica Veterinaria e Patologia Animale, and ${ }^{* *}$ Dipartimento di Biologia Evoluzionistica Sperimentale, Università di Bologna, Italy.

*** Facultad de Biologia, Pontificia Universidad Católica del Ecuador, Quito, Ecuador.

**** Dipartimento di Scienze Morfologiche e Medico Legali, Università di Modena e Reggio Emilia, Modena, Italy.

Correspondence: Prof. M. Trentini, Dipartimento di Biologia evoluzionistica sperimentale, Università di Bologna, via Selmi 3, 40126 Bologna, Italy.

Fax : 0039051251208 - Tel. : 00390512094162

E-mail: trentini@alma.unibo.it
}

ixty four gravid females in various stages of development and two male Tunga sp. were examined; $\bigcup$ all were from Santa Isabel in the province of Azuay in the Ecuadorian Andes ( $3^{\circ} 15^{\prime} 61.0^{\prime \prime} \mathrm{S}$ and $79^{\circ}$ $18^{\prime}$ 67.4" W, at $1,400 \mathrm{~m}$. a. s. 1.). The female specimens were taken from goats (49 specimens), pigs (six specimens) and cattle (nine specimens) at a slaughterhouse or from nearby breeding sites. The male specimens were captured using humans as bait in a goat shed. Most of the females were stored in $70 \%$ ethanol and examined with a stereoscopic dissecting microscope. To study particular morphological details some specimens were dissected and drawn with a camera lucida. Histological sections were stained with haematoxylin and eosin, PAS and Masson Goldner Trichromic. The males were cleared and permanently mounted in Hoyer's medium. Some gravid females were dehydrated in an ascending series of ethanol from 
$70 \%$ to $100 \%$, mounted on a stub, sprayed with gold and observed under a JEOL 5200 scanning electron microscope (SEM). Another 50 gravid females of Tunga sp. from pigs from other areas in the Andes of Ecuador (Pelileo at $2,592 \mathrm{~m}$ in the province of Tungurahua and Riobamba at $2,754 \mathrm{~m}$ in the province of Chimborazo) were examined to see if the new species of Tunga was also present in localities $250-300 \mathrm{~km}$ north of Santa Isabel. Our specimens were compared with males and gravid females of $T$. penetrans from Africa and Venezuela from humans, pigs and dogs, and with Tunga spp. in the collection of the Natural History Museum, London.

\section{RESULTS}

The specimens of Tunga sp. from Santa Isabel collected from goats, pigs and cattle have morphological characters showing they represent a previously undescribed species. The chigoes from
Africa, Venezuela and other places in Ecuador were identified as Tunga penetrans.

\section{DESCRIPTION}

Type material

The gravid female holotype from Santa Isabel, $3^{\circ} 15$ ' 61.0" S - 79 18' 67.4" W, 1,400 m.a.s.1., province of Azuay, Ecuador, from Capra bircus, 15.X.1990, leg. N. Minerva. Paratypes of both sexes from the same locality are deposited in the Biology Department of the University of Bologna, Italy.

\section{Adult gravid female (Fig. 1)}

Globular, slightly compressed in an antero-posterior direction (Fig. 1A) with the greatest dimension reaching about $6 \mathrm{~mm}$ in width. Anteriorly, there are three humps on the abdomen (Fig. 1A, C) easily visible to the naked eye and surrounding the head and the thorax, rendering the latter structures invisible on profile (Fig. 2A). The three humps, one ventral and two late-
A

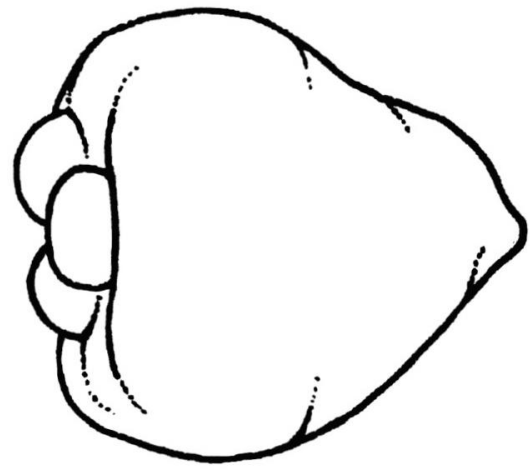

$$
2 \mathrm{~mm}
$$

C

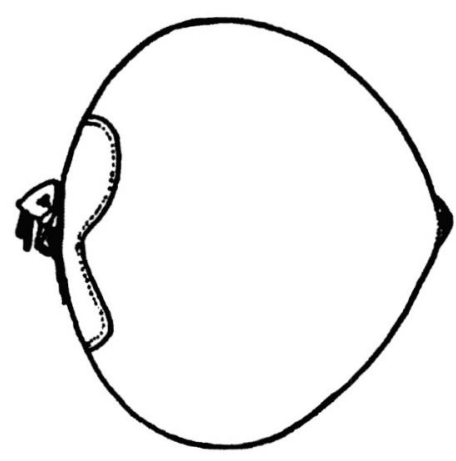

B

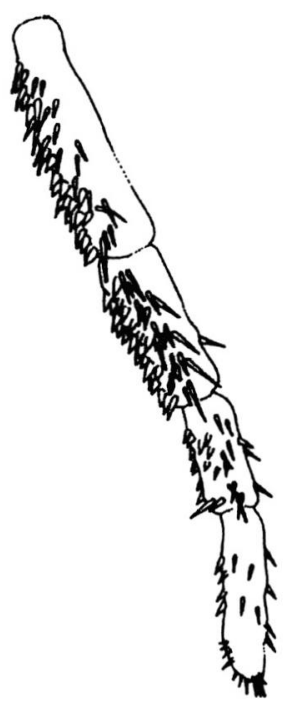

$\overline{50 \mu \mathrm{m}}$

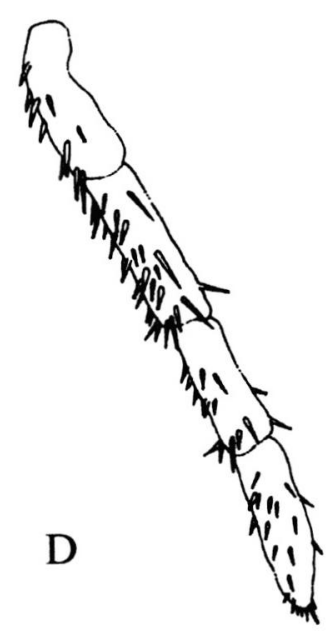

Fig. 2. - (A) Gravid female of Tunga trimamillata in profile. (B) Maxillary palpi of Tunga trimamillata female. (C) Gravid female of Tunga penetrans in profile. (D) Maxillary palpi of Tunga penetrans female. 
rodorsal, are similar to each other having a semispherical form, each with a diameter which can be as much as $1.2 \mathrm{~mm}$ (Fig. 1A, C); they are semi-transparent and some ova are more or less plainly visible within them. The eye is large, pigmented and measures $42 \times 65 \mathrm{~mm}$ (Fig. 1B). The maxillary palpi are covered by numerous, thick, short spines and long bristles and have the first proximal segment clearly longer than the other three; the third is the shortest (Fig. 1D, Fig. 2B). The last tarsal segment of the legs is long and narrow, about eight times longer than its width (Fig. 1B). Posteriorly, the last abdominal segments form a large visible cone that is sometimes hollowed in the penultimate segments; the respiratory spiracles of abdominal segments V to VIII are cleary visible (Fig. 1E, F). We don't describe unexpanded females, none being captured.

\section{Male (Fig. 1G)}

The length of the body is about $1 \mathrm{~mm}$. The respiratory spiracles, all of similar size, are visible on the abdomen. Apparently, the genitalia are similar to those of $T$. penetrans. The few male specimens presently available are insufficient for a more detailed description. We are studying other specimens recently collected on the field by one of us (M.L.F.) and they will be referred to another study.

\section{Diagnosis}

The most striking morphological feature of T. trimamillata which immediately differentiates this species from the other nine described species of the same genus is the presence of the three humps of the abdomen and the impossibility of seeing the head and thorax of the gravid female in profile (Fig. 2A). The humps are absent in T. penetrans, T. travassosi Pinto
\& Dreyfus, 1927, T. bondari Wagner, 1932 and T. caecata Enderlein, 1901 and the head and thorax are either visible in profile ( $T$. penetrans, $T$. travassosi) (Fig. 2C and Fig. 3A, C) or, when concealed within the abdomen, are invisible ( $T$. bondari, $T$. caecata). In T. terasma Jordan, 1937, T. caecigena Jordan \& Rothschild, 1921, T. callida Li \& Chin, 1957 and T. monositus Barnes \& Radovsky, 1969, four or eight lobes and humps are present and the head and thorax are either visible in profile ( $T$. terasma) or, when covered by the humps, invisible (T. caecigena, T. callida, T. monositus) (Table I). The expanded female of T. libis Smit, 1962 is at present unknown.

Tunga trimamillata is similar to T. penetrans in having the pronotum completely fused dorsally with the mesonotum and in having pigmented eyes. In addition to the three humps, there are three other features that distinguish the new species from $T$. penetrans, namely: a) size: the bodies of both male and female T. trimamillata are much larger than those of $T$. penetrans; b) the maxillary palpi of $T$. trimamillata are covered with thick, short spines and long bristles compared to only long and short bristles in T. penetrans (Fig. 1D, 3B, 2B, 2D);

C) the first proximal segment of the maxillary palpi of T. trimamillata is longer than the others (Fig. 1D, Fig. 2B) whereas, in $T$. penetrans, the second is the longest (Fig. 2D) (Westwood, 1840; Hopkins \& Rothschild, 1953; Jordan, 1962).

\section{Pathology}

Macroscopically, the lesions due to Tunga trimamillata are more evident than those due to T. penetrans and, when the parasite is extracted from the skin, we can see with the naked eye the hump-prints at the bottom of the "hole" (Fig. 4A)

\begin{tabular}{|c|c|c|c|c|}
\hline Species & $\begin{array}{l}\text { Abdomen } \\
\text { shape }\end{array}$ & $\begin{array}{l}\text { Head and thorax } \\
\text { in profile }\end{array}$ & $\begin{array}{l}\text { Geographical } \\
\text { distribution }\end{array}$ & Host \\
\hline T. trimamillata $\mathrm{n} . \mathrm{sp}$. & globular & not visible, among 3 humps & Ecuador & goat, pig, cow \\
\hline T. penetrans (L., 1758) & globular & visible & $\begin{array}{l}\text { Latin America and Africa } \\
\text { South of the Sahara }\end{array}$ & $\begin{array}{l}\text { human, pig, dog, cow, } \\
\text { horse, donkey, etc. }\end{array}$ \\
\hline T. Travassosi Pinto \& Dreyfus, 1927 & globular & visible & Brazil & $\begin{array}{l}\text { amardillo } \\
\text { (Dasypus novemcinctus) }\end{array}$ \\
\hline T. bondari Wagner, 1932 & globular & $\begin{array}{l}\text { not visible, concealed within } \\
\text { abdomen }\end{array}$ & Brazil & $\begin{array}{l}\text { ant-eater } \\
\text { (Tamandua tetradactyla) }\end{array}$ \\
\hline T. terasma Jordan, 1937 & quadrilobate & visible & Brazil & $\begin{array}{l}\text { amardillo (Cabassous } \\
\text { unicinctus) }\end{array}$ \\
\hline T. caecata Enderlein, 1901 & globular & $\begin{array}{l}\text { not visible, concealed within } \\
\text { abdomen }\end{array}$ & Brazil & $\begin{array}{l}\text { Rattus rattus, } R \text {. norvegicus, } \\
\text { Mus musculus }\end{array}$ \\
\hline T. caecigena Jordan \& Rothschild, 1921 & elliptical & not visible, among 4 humps & China, Japan & Rattus rattus, $R$. norvegicus \\
\hline T. callida Li \& Chin, 1957 & globular & not visible, among 4 humps & China & rodents \\
\hline T. libis Smit, $1962\left(^{*}\right)$ & not described & not described & Ecuador, Chile & Akodon mollis \\
\hline T. monositus Barnes \& Radovsky, 1969 & ovoid & not visible, among 8 humps & Mexico, USA & rodents \\
\hline
\end{tabular}

(*) Smit $(1962,1968)$ described only one male from Ecuador and two unexpanded females from Chile.

Table I. - Species of the genus Tunga: gravid females characteristics. 

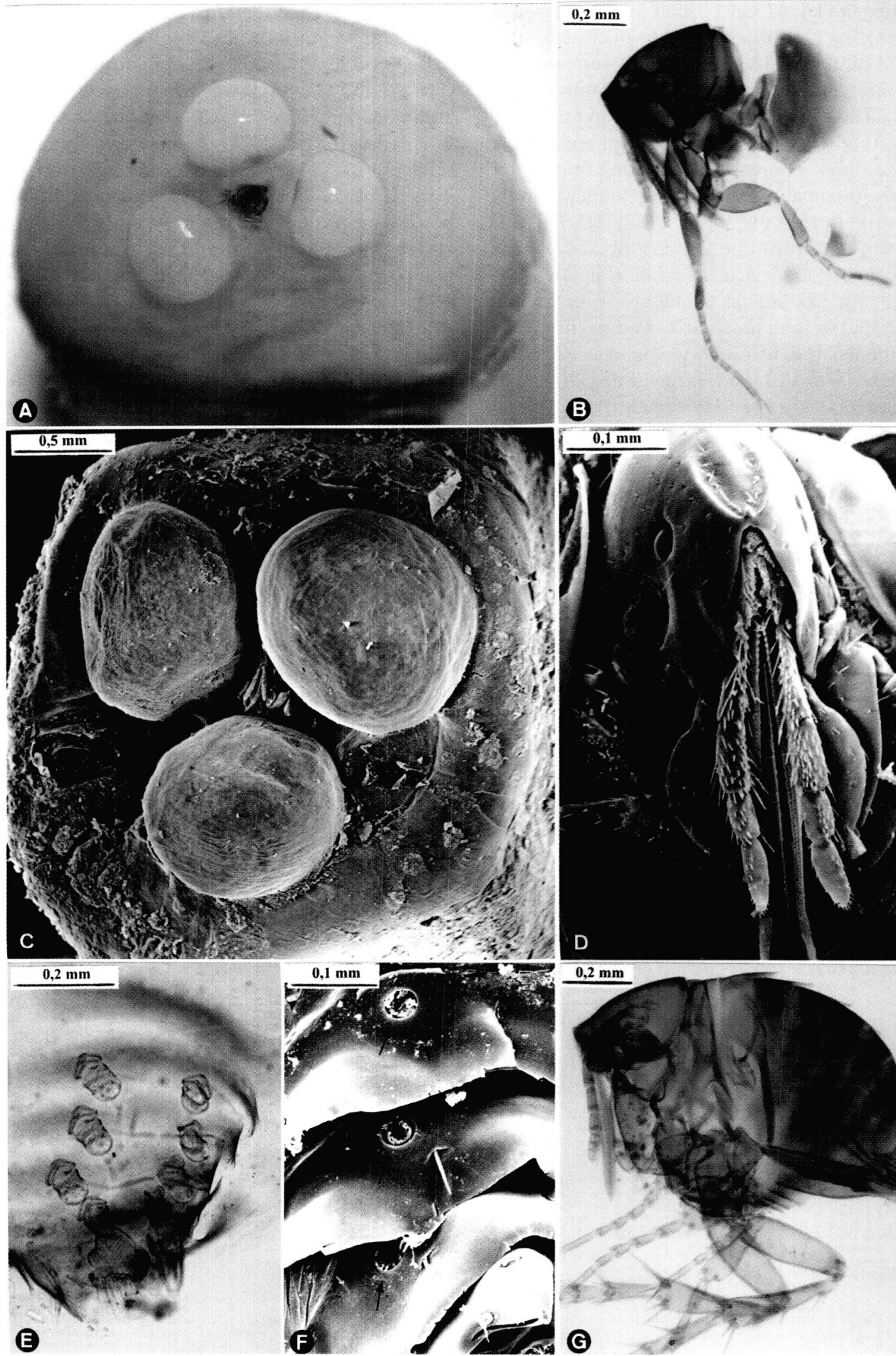

B
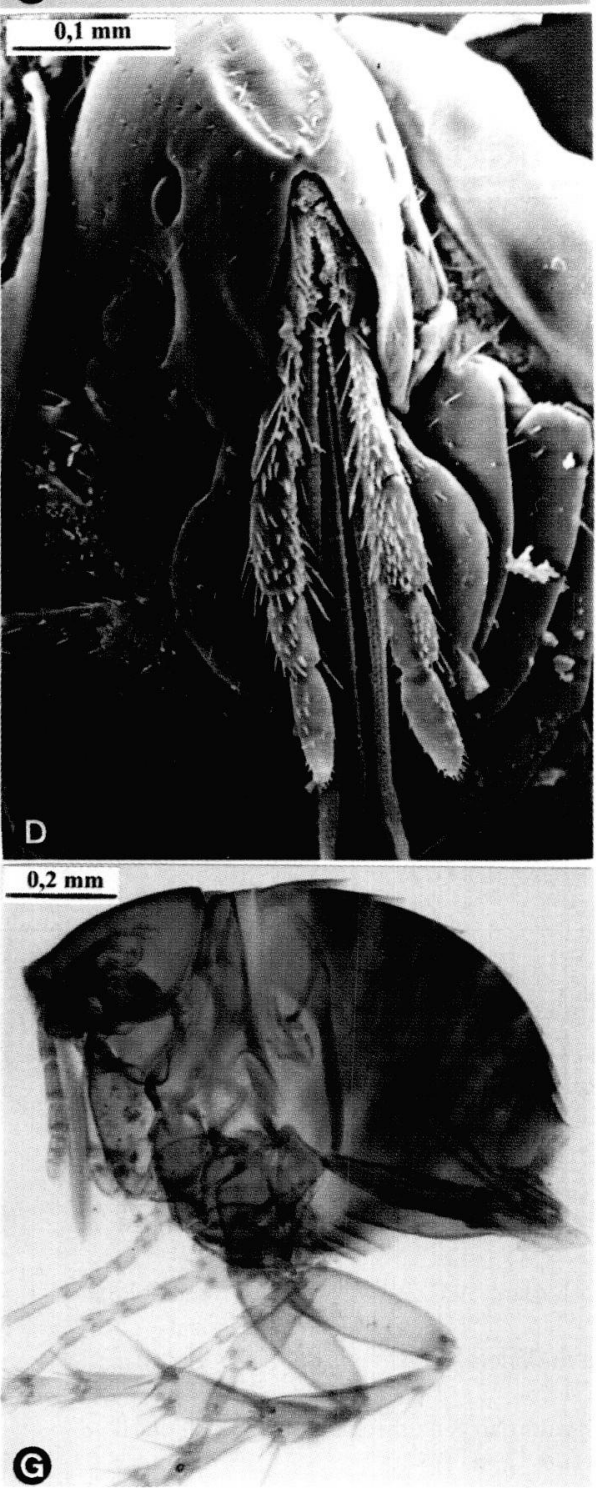

Fig. 1. - Tunga trimamillata from goats, Ecuador. (A) Anterior extremity of gravid female. (B) Head and thorax of gravid female separated from abdomen (Hoyer's medium). (C) Anterior extremity of gravid female, SEM. (D) Details of head and thorax of gravid female in frontal view, SEM. (E) Respiratory spiracles of last abdominal segments of gravid female (Hoyer's medium). (F) Respiratory spiracles (arrows) of $5^{\text {th }}, 6^{\text {th }}$ and $7^{\text {th }}$ abdominal segments, SEM. (G) Male (Hoyer's medium). 

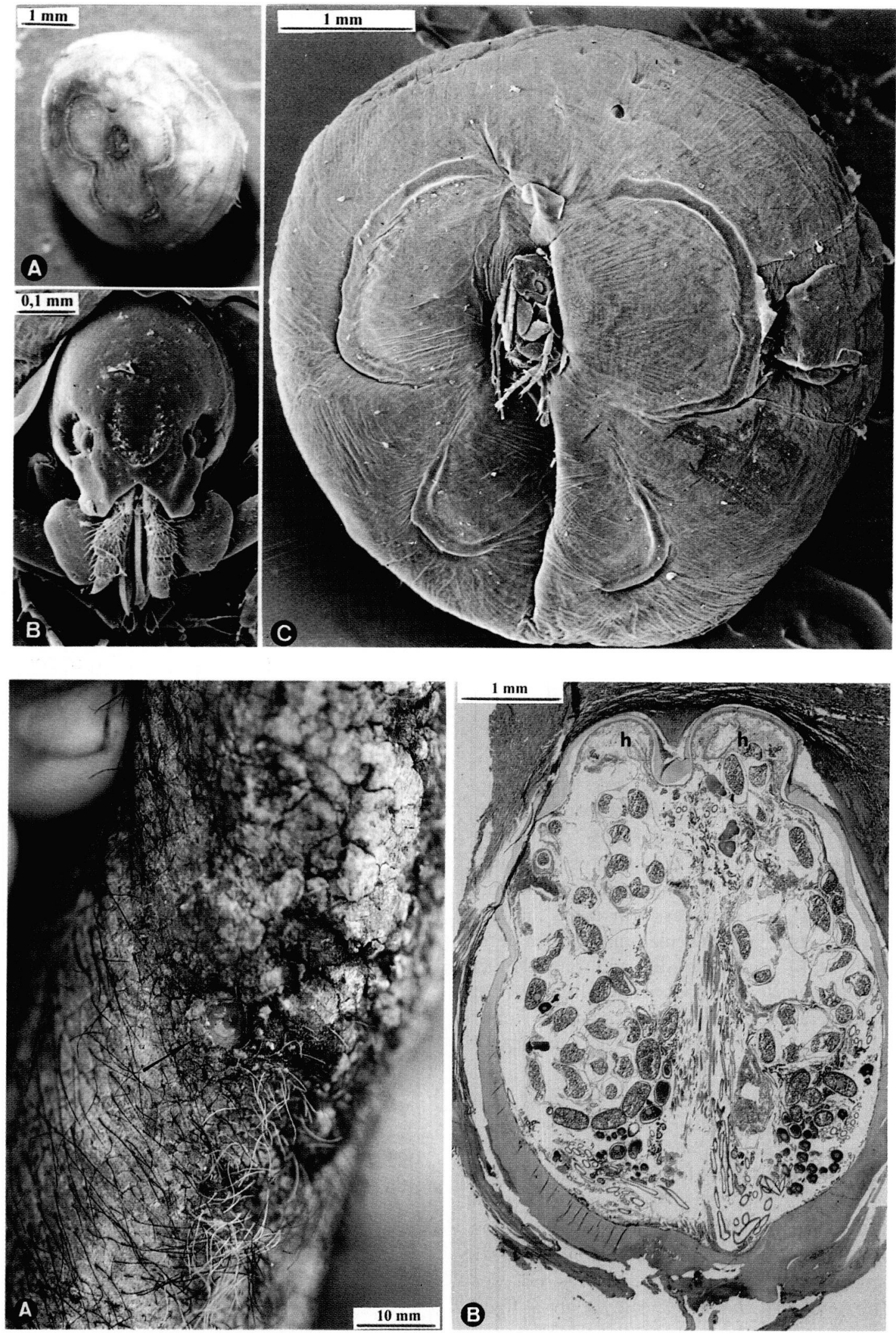

Fig. 3. - Tunga penetrans from human, Madagascar. (A) Gravid female. (B) Frontal view of head and thorax of gravid female, SEM. (C) Anterior extremity of a gravid female, SEM

Fig. 4. - (A) Lesion due to Tunga trimamillata from pig. (B) Histological section of gravid female of Tunga trimamillata embedded in skin of a bovine (Trichromic Masson Goldner Stain). Note the humps (h). 
There are no apparent differences in the histopathological changes in the host skin caused by T. trimamillata and T. penetrans (Pampiglione et al., 1998). The parasite is situated in the epithelial tissue covered almost completely by the considerably thinned horny layer, so that it is deeply inserted in the basal layers of the skin of the host. Communication with the outside is through a small foramen that allows the parasite to respire, excrete and oviposit. A moderate inflammatory infiltration, principally consisting of eosinophilic granulocytes, neutrophils, lymphocytes, and rarely plasmacells and histiocytes, is usually present near the cephalic extremity of the parasite. The epithelial layer frequently shows acanthosis and hyperkeratosis with a marked irregular surface (Fig. 4B).

Seasonality

Tunga trimamillata was collected exclusively during the dry season, i.e. from June to October.

Local name

Locally, the Santa Isabel chigoe is called "Nigua"; this is the same name used for $T$. penetrans in other regions of Ecuador and Latin America too.

\section{DISCUSSION}

T

The nine described species of chigoes of the genus Tunga are subdivided into two groups - penetrans group and caecata group - according to the presence or absence of eyes, or eye pigment, and whether or not the pronotum is fused with the mesonotum (Smit, 1962). The species of the first group are parasites of edentates, armadillos, humans and various domestic and wild mammals; those of the second group afflict, mainly, murine and sigmodontine rodents. Tunga trimamillata belongs to the penetrans group. The geographical distribution, hosts and important morphological characteristics of each species are shown in Table I.

A male of Tunga libis, found on the sigmodontine rodent, Akodon mollis (Thomas, 1894), in Riobamba, Ecuador, was described by Smit (1962). The male of T. trimamillata differs from that of $T$. libis by a) its larger size, b) the claspers, c) the $5^{\text {th }}$ tarsal segment and d) the maxillary palpi. In the original description, T. libis was placed, and it's unquestionably so, in the caecata group even though the eye was not described. The eye was, however, shown in a figure where it is close to the dorsal margin of the head than that of T. trimamillata (Fig. 1G). It was not possible to compare the unexpanded female of $T$. libis, described by Smit (1968), because we didn't capture this stage of T. trimamillata.
It is interesting to note that, with the exception of T. penetrans, Tunga spp. almost always parasitise a single species of vertebrate host, or a few closely related species. T. trimamillata has already been collected from three different species (goats, pigs and cattle) and it is probable that, like T. penetrans, it can also parasitise other species of animals, both domestic and wild, as well as humans. Pending research is verifying the hosts and the geographic distribution.

We checked the literature of the 1800 s and early 1900s, when the multiplicity of Tunga species was not known, to see if any early illustrations of Tunga could be referred to T. trimamillata, but all depicted T. penetrans. However, in a recent publication (Georgi \& Georgi, 1991), we found photographs (Fig. 1.21 and Tables 1-6) of a gravid female classified as Tunga sp. from a pig in Ecuador (locality not specified) in which the presence of three clearly visible anterior humps suggests the specimen was $T$. trimamillata.

\section{ACKNOWLEDGEMENTS}

W e thank Nicola Minerva and Giuseppe Diegoli for kindly providing some specimens of the chigoes from Ecuador and Mario Marini and Salvatore Giannetto for help with scanning electron microscopy. Finally, we thank Theresa Howard for assistance in examining the collection of chigoes in the Entomology Department, Natural History Museum, London, Joanna Kapusta of the same department for help with relevant literature, Robert Killick-Kendrick for revision of our manuscript and Ayodhya P. Gupta for his valuable advices and suggestions. This investigation was supported by grant from the MIUR and from the Foudazione Cassa di Risparmio in Bologna.

\section{REFERENCES}

Georgi J.R. \& Georgi M.E. Canine clinical parasitology. Lea \& Febiger, Philadelphia, 1991

Hopkins G.H.E. \& RothSCHILD M. An illustrated catalogue of the Rothschild collection of fleas (Siphonaptera) in the British Musem (Natural History) Vol. I. Tungidae and Pulicidae. The Trustees of the British Musem, London, 1953, 38-50.

Jordan K. Notes on Tunga caecigena (Siphonaptera: Tungidae). Bulletin of the British Museum (Natural History) Entomology (London), 1962, 12, 353- 364.

Pampiglione S., Trentini M., Mattei Gentili F., Mendes J.L.X., Pampiglione C. \& Rivasi F. Tunga penetrans (Insecta: Siphonaptera) in pigs in São Tomé (Equatorial Africa): epidemiological, clinical, morphological and histopathological aspects. Revue d'élévage et de médecine vétérinaire des pays tropicaux, 1998, 51, 201-205. 
Pampiglione S., Trentini M., Fioravanti M.L., Onore G., RIVASi F. A new species of Tunga (Insecta, Siphonaptera) in Ecuador. Parassitologia, 2002, 44 (Suppl. 1), 127.

Smit F.G.A.M. A new sand-flea from Ecuador. The Entomologist, 1962, 95, 89-93.

SmIT F.G.A.M. Siphonaptera taken from formalin-traps in Chile. Zoologischer Anzeiger, 1968, 180, 220-228.

Traub R. Siphonaptera from Central America and Mexico. Fieldiana: Zoology Memoirs, 1950, 1, 1-127.

Trentini M., Pampiglione S., Giannetto S. \& Finocchiaro B. Observations about specimens of Tunga sp. (Siphonaptera, Tungidae) extracted from goats of Ecuador. Parassitologia, 2000, 42 (suppl. 1), 65.

Trentini M., Pampiglione S., Marini M., \& Giannetto S. Una probabile nuova specie di pulce penetrante nell'Ecuador (Siphonaptera, Tungidae). $62^{\circ}$ Congresso Nazionale Unione Zoologica Italiana, Sanremo, 23-27 settembre 2001, 65-66.

Westwood F.L.S. On the characters of the Chigoe or Jigger. Transaction of Entomological Society, 1840, 2, 199-203.

Reçu le 6 novembre 2002

Accepté le 2 janvier 2003 